
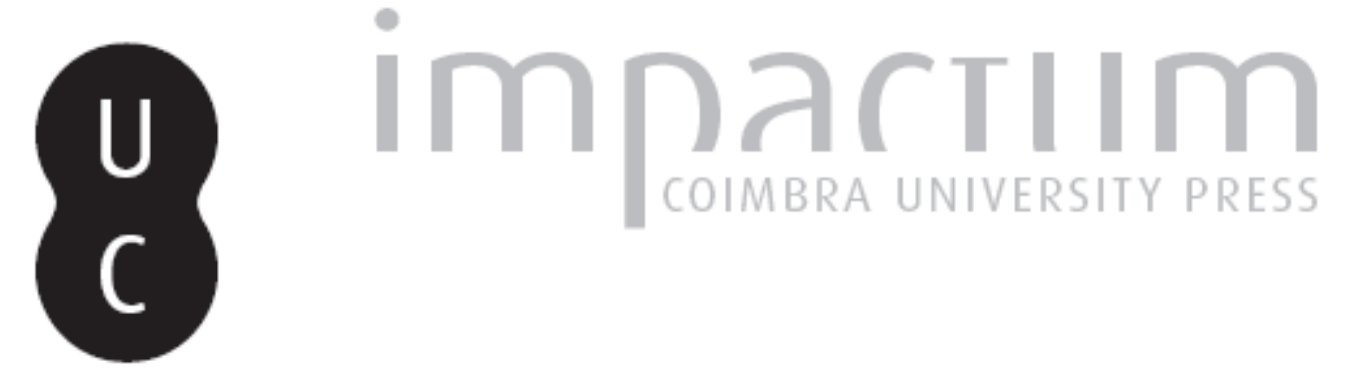

\title{
[Recensão a] Quem Paga o Estado Social em Portugal? Onde nos Leva esta Crise Económica? O Estado de Bem-estar Social Europeu Tem Futuro? Dívida de todos ou negócio de alguns?
}
Autor(es):
Oliveira, Ana Rita Veleda

Publicado por: Imprensa da Universidade de Coimbra

URL

persistente:

URI:http://hdl.handle.net/10316.2/36817

DOI:

DOI:http://dx.doi.org/10.14195/1647-8622_13_24

Accessed : $\quad$ 26-Apr-2023 10:30:57

A navegação consulta e descarregamento dos títulos inseridos nas Bibliotecas Digitais UC Digitalis, UC Pombalina e UC Impactum, pressupõem a aceitação plena e sem reservas dos Termos e Condições de Uso destas Bibliotecas Digitais, disponíveis em https://digitalis.uc.pt/pt-pt/termos.

Conforme exposto nos referidos Termos e Condições de Uso, o descarregamento de títulos de acesso restrito requer uma licença válida de autorização devendo o utilizador aceder ao(s) documento(s) a partir de um endereço de IP da instituição detentora da supramencionada licença.

Ao utilizador é apenas permitido o descarregamento para uso pessoal, pelo que o emprego do(s) título(s) descarregado(s) para outro fim, designadamente comercial, carece de autorização do respetivo autor ou editor da obra.

Na medida em que todas as obras da UC Digitalis se encontram protegidas pelo Código do Direito de Autor e Direitos Conexos e demais legislação aplicável, toda a cópia, parcial ou total, deste documento, nos casos em que é legalmente admitida, deverá conter ou fazer-se acompanhar por este aviso. 


\section{estado-providência}

ESTUD OSD OSÉCULO

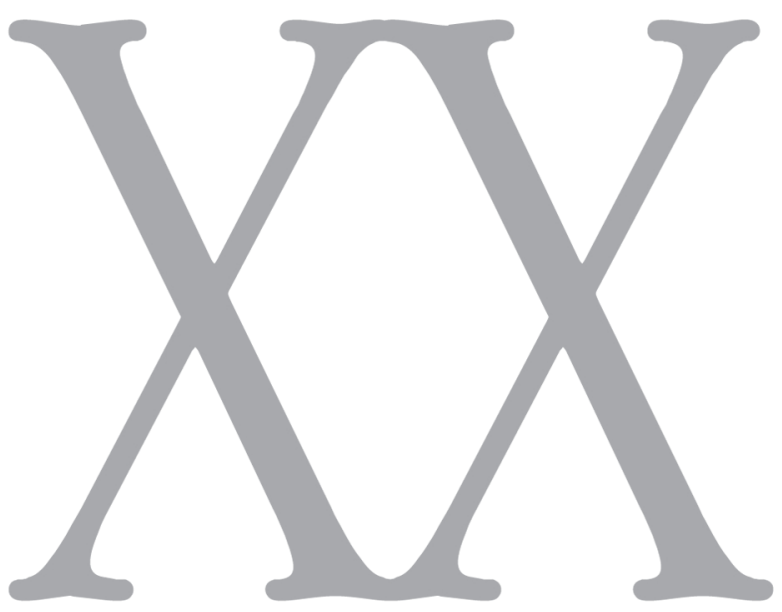

número 13 • 2013

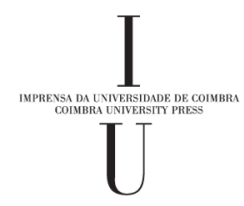


sempre ascendentes, da importância da competitividade, justificando o desemprego forçado não com a falta de qualidade dos despedidos, mas com a fatalidade dos números e, se se utiliza um adjectivo, a falta de "empreendedorismo" dos que ficam sem "ganha-pão". Afinal o mesmo Einstein que, com Arnold Berliner ou com Freud, pensaram numa sociedade de homens de ciência que equacionasse constantemente o mundo do saber, o que hoje não sucede, verificando-se sim, em muitas situaçóes, o mundo da ciência e da tecnologia acríticas e dos gestores que gerem a sociedade capitalista sem ética. Até as universidades e mesmo as universidades ditas eclesiásticas, no nosso caso as católicas, não estão tanto preocupadas com a moral da produção e da multiplicação financista, e das suas consequências, e sim mais com a boa gestão do capital.

Afinal tudo isto é velho, conforme verificam os autores deste livro e historiadores como eu. Jacques Julliard, numa obra de 1977 intitulada Contre la politique professionnelle - que tinha como objectivo criticar a política como profissão e concorrer com sugestóes, de que só algumas foram ultimamente postas em prática, para sua desprofissionalização — , descrevia o conflito que se verificava entre a "sociedade civil" em desenvolvimento e a "sociedade política” com as suas estratégias de poder, falando a este propósito da "politique politicienne", e distinguia mesmo, neste sentido, o "socialismo político" do "socialismo social". O "sistema" é o mesmo que nos idos anos 70 e, por isso, até a França se destruiu como "mundo cultural". Da Inglaterra, fica como espuma intensa, o uso e o abuso da sua língua de comunicação e menos da sua cultura. Da Alemanha fala-se menos da língua (que nunca se vulgarizou) e da sua notável cultura do que do poder de organização, com um olhar de superioridade para com "os povos do sul".

No Coutry for Old Men (2007), Este Mundo não é para Velhos, o filme dos irmãos Coen, cheio de violência como é violento este mundo, aí está como paradigma. Mas ao título do livro que o inspirou, de Cormac McCarthy, devemos somar a ideia de que este mundo não é para velhos nem para novos. Por isso Raquel Varela recorreu à dura imagem do eclesiástico rebelde Jonathan Swift (o da fábula de Gulliver), que, na sátira política $A$ modest proposal (1729), sugeria que os pais comessem os filhos para acabar com a fome na Irlanda.

Não li este livro como especialista — já o disse - mas como académico e como cidadão. É como tal, e como historiador que vai pensando o mundo, que teci estas consideraçôes.

Luís Reis Torgal

Investigador Integrado do CEIS 20

Quem Paga o Estado Social em Portugal? Onde nos Leva esta Crise Económica? O Estado de Bem-estar Social Europeu Tem Futuro? Dívida de todos ou negócio de alguns? Lisboa: Bertrand editora. 2012. 470 páginas

De inspiração marxista, referida explicitamente em vários momentos, os 16 artigos que compóem este volume são prefaciados por Maria Luísa Fattorelli, auditora fiscal e sindicalista brasileira. Devido à dívida pública, que oculta a verdadeira crise do sector bancário e o enorme défice do sector financeiro, a coordenadora nacional da campanha permanente Auditoria Cidadã da Dívida considera que se vivem duros planos de austeridade fiscal na Europa, com carências comparáveis aos tempos de guerra. Porém, os contributos deste livro não 
focam apenas a crise na Europa, nem só o tempo presente. Procuram desmascarar o vigente discurso neoliberal, que oculta lutas conquistadas pelos trabalhadores ao longo de décadas e que os engana, dizendo-lhes que os impostos que pagam não são suficientes para cobrir os seus próprios benefícios sociais.

Raquel Varela, a historiadora portuguesa presidente da International Association Strikes and Social Conflicts, fala-nos, na introdução, de duas grandes vítimas das medidas contracíclicas adoptadas em resposta a esta crise: o desemprego em massa, em Portugal e no mundo, e a ideia de uma Europa fraterna e unida. A conjuntura (as conjunturas) de crise estrutural que se vivem no mundo e na Europa e a esperança na união dos povos desta Comunidade como horizonte de solução, adivinham-se subjacentes a todo o volume. A perspectiva, marxista, não é, porém, de vitimização, uma vez que são relatadas lutas e conquistas dos trabalhadores e movimentos sociais e apontadas soluções para os tempos actuais de dura austeridade.

A entrevista com Éric Toussaint, membro da ATTAC e talvez o crítico mais incisivo das instituiçóes europeias neste volume -, foca-se na responsabilidade dos bancos privados. Dando o exemplo da Grécia, critica o BCE por privilegiar os interesses de banqueiros privados devendo, segundo o autor, a avaliação de riscos caber a organismos públicos. Como solução, sugere uma moratória unilateral de reembolso da dívida pública e a constituição de uma auditoria cidadá, sem participação governamental. Os movimentos sociais, a sociedade civil de base, internacionalizados, podem criar uma força de impacto de combate à austeridade.

Os artigos da segunda parte do livro, de história económica e de economia política, fornecem-nos instrumentos teóricos que, numa segunda fase, permitirão ler as análises aplicadas aos casos português e europeu.
Para entendermos a "grande depressão do século XXI», torna-se útil analisar a Crise de 1929. Osvaldo Coggiola, o historiador argentino autor do artigo «A Crise de 1929 e a Grande Depressão da Década de 30", revê o contexto histórico, económico e político desta crise anterior, originada pelo crack da Bolsa de Nova Iorque, que quase destruiu o sistema financeiro internacional. Trotsky - que, em 1934, considerava já estar a guerra na agenda política internacional -, propôs a criação, nos EUA, de um Partido Trabalhista. Porém, a solução, à época, foi a devastadora II Guerra Mundial, que permitiu aos EUA reerguerem-se da recessão através de uma economia de guerra, que trouxe de volta à Europa, e ao mundo, a tríade guerra-barbárie-revolução. A Grande Depressão acentuou todas as contradiçóes do capitalismo. O papel dos governos náo deve ser posto de parte, como advogaram os neoclássicos. Coggiola reitera a importância do enfoque na esfera produtiva, menosprezada por monetaristas e keynesianos, que privilegiam a esfera da circulação. Na altura da crise, nos anos 30 do século XX, surgiram importantes movimentos de trabalhadores organizados. Coggiola fala-nos ainda de Inglaterra, França, Rússia, do Nazismo e da Guerra Civil Espanhola, momento tão importante para as lutas republicanas.

Em «Observaçóes em Torno do Movimento Real dos Ciclos e das Crises Económicas», José António Martins, economista brasileiro, relata-nos as crises globais que estão a explodir no início do século XXI, sendo a indústria dos EUA reguladora da produção mundial. Segundo o autor, há uma diferença entre os representantes reunidos nas Cimeiras de Davos e as "profundezas abstractas do inferno da produção", encontrando-se o limite do capital na evolução cíclica da 
produtividade da força de trabalho, ou seja, na exploração desta. A violência da exploração, em tempo de crise, gera mais violência, ocorrendo as explosôes das crises capitalistas no ponto mais elevado da curva de acumulação. O lucro, a mais-valia do capitalismo, corresponde à produtividade do trabalho.

Em «Interpretaçóes sobre o Capitalismo Actual e a Crise Económica», Reinaldo António Carcanholo, economista político da América-Latina, reitera a importância da teoria do valor de Marx, sendo os conceitos de «capital fictício» e de "lucros fictícios» fundamentais. A riqueza económica é consequência do trabalho produtivo, que produz mais-valia. Ora, as políticas neoliberais aumentam a exploração do trabalho, vivendo o sistema capitalista uma crise endémica e estrutural. O autor aponta como solução a destruição progressiva do sistema capitalista pelas suas vítimas.

Em «O Papel e o Significado da Dívida Pública», Paulo Nakatani, economista brasileiro, explica-nos que a dívida pública, contratual e mobiliária, surge dos défices orçamentais dos governos. O BCE e o Tesouro mais não fazem do que converter défice em dívida interna, que gera nova dívida determinando, hoje, o sistema de crédito a acumulação e a reprodução do capital. Mais uma vez se privilegiam as teorias marxistas, em detrimento das teorias neoclássicas e keynesiana. Governa-se, hoje, no modelo neoliberal determinado pelo Consenso de Washington, sob as determinaçóes do mercado, dominando a esfera financeira a esfera produtiva. O FMI, através dos superavits primários, obriga os governos a reduzirem os gastos públicos. As reservas internacionais convertem-se em dívida interna, que, devido aos juros, se converte em novas dívidas. A reprodução do capital na esfera puramente financeira requer uma desvalorização do capital fictício acumulado, resposta necessária também à escala internacional.

O historiador brasileiro Valério Arcary é autor do artigo "A Vertigem da Decadência e os Desafios do Futuro: Crises Económicas, Regressão Histórica e Conflitos Sociais». Neste, esboça-se a seguinte hipótese: «a regulação social realizada pelos Estados europeus entrou em colapso de forma irreversível depois da precipitação da crise económica mundial em 2008.» (p. 413). O keynesianismo fiscal dos últimos anos - e o pré-keynesianismo alemão de Merkel, com a sua política contraccionista - tem sido perigoso, sobretudo para economias fragilizadas como Portugal e Grécia, que em 2011 sofreram perigo de default. Advoga-se um mercado mundial mais internacionalizado e um sistema de Estados mais rígido. Alerta-se, ainda, para as diferenças entre economistas e historiadores, pois as crises sofrem o risco de análises economicistas, quando a sua solução deve ser político-social.

Cláudio Katz, economista argentino, contribui com "Liçôes da Argentina para a Grécia» (pp. 357-374). Os bancos publicitam chantagens, por intermédio das empresas de rating, sendo a experiência Argentina a prova de que os refinanciamentos são inúteis. Preconiza, como solução, a suspensão de pagamentos, tal como aconteceu na Argentina, que declarou incumprimento de forma involuntária, quando o país ficou sem fundos. A Grécia deve fazer, de imediato, uma auditoria da dívida. Na Argentina ocorreu, ainda, a nacionalização dos bancos, tornando-se necessário estabelecer controlo sobre os movimentos de divisas e capitais. A periferia europeia deve seguir o modelo argentino e ser ainda mais audaz, com a generalizaçáo da acção popular, na expansão da qual as redes sociais podem ser úteis, provocando efeito dominó, semelhante ao que ocorreu no mundo árabe. 
Também Savas Michael-Matsas, activista político trotskista grego, nos fala do seu país em "A Grécia e o Declínio da Europa». A Grécia é o elo mais fraco na cadeia capitalista internacional e europeia. A grave recessão grega repercutiu-se de imediato na Irlanda e em Portugal - atingindo o próprio centro da União Europeia -, que se viram obrigados a aceitar pacotes de «resgate» e medidas de austeridade semelhantes. Em 2011, a dívida grega ascendia a $169 \%$ do PIB, numa eurozona com um frágil sistema bancário e economia em contracção. Vivemos uma crise histórica de superprodução de capital sem precedentes, no contexto da qual a própria História acelerou o seu ritmo, sem termos uma estratégia de longo prazo para resolver a recessão. Há que nacionalizar os bancos e todos os sectores estratégicos da economia, reorganizada em novas bases socialistas, sob controlo dos trabalhadores, numa União dos Estados Socialistas Europeus.

Felipe Donnier e Gilberto Calil, historiadores brasileiros, em «Crise Económica e Democracia Representativa no Sul da Europa», reafirmam a actualidade de Marx e Engels, mencionando, ainda Boaventura de Sousa Santos e Otelo Saraiva de Carvalho. O sociólogo português afirmou ao jornal $i$ que "A Europa tem a democracia suspensa", enquanto Otelo frisa a necessidade de uma nova actuação dos militares. Portugal é reconhecido pela OMT como o país em que mais cresceu a precariedade laboral nos últimos cinco anos, tendo no nosso país o orçamento para 2012 imposto drásticos cortes nas verbas para alguns dos sectores mais importantes, como a saúde e a educação. Para os dois autores, a burguesia portuguesa procura consenso em torno das suas próprias medidas de austeridade. Nas democracias representativas do sul da Europa, vive-se hoje um enorme fosso entre quem governa e as classes menos privilegiadas.
Virginie de Romanet, do CADTM, fala-nos do "Os Planos de Austeridade na Europa». Através de tabelas explicativas, esta autora de vários artigos sobre a dívida contrasta dados referentes a: Função Pública, Reformas da Assistência Social, Impostos Directos e Indirectos/ Taxas Diversas, Despesas Públicas Privatizaçóes. As suas tabelas permitem-nos comparar a Alemanha, Áustria, Espanha, Finlândia, França, Grécia, Hungria, Irlanda, Itália, Letónia, Lituânia, Polónia, Portugal, República Checa, Roménia e Reino Unido. Sem mencionar datas, a autora relata que, por exemplo, em Portugal (p. 410), deu-se o congelamento dos salários da função pública por quatro anos e a substituição de um reformado em cada dois; um recuo da idade da reforma, congelamento das pensóes e dos subsídios sociais, diminuição do rendimento social de inserção, supressão dos subsídios de inserção para os jovens, redução do orçamento da segurança social, saúde e transportes públicos; aumento de $1,5 \%$ do subsídio do imposto sobre o rendimento, e aumento do IVA de $21 \%$ para $23 \%$.

"Quem Paga o "Bem-Estar” no Estado-Providência?» Um Estudo sobre vários Países», de Anwar Shaikh, economista anglo-paquistanês, fala dos violentos ataques que o Estado Social começou a sofrer, apresentando as suas conclusóes de um estudo em seis países avançados da OCDE. Os gastos com benefícios sociais são financiados com os impostos pagos pelos contribuintes! O Estado-providência perpetua o desemprego que ele próprio cria! Neste artigo, tornam-se imprescindíveis as relaçóes entre o Estado e o trabalho, focando-se a metodologia do salário social líquido. No fim de contas, verifica-se que o elo causal entre as despesas sociais e a quebra do crescimento é uma invenção dos neoliberais. 
Em «Quem Paga o Estado Social em Portugal?», de Renato Guedes e Rui Viana Pereira, respectivamente membro e membro co-fundador do CADPP, a situação portuguesa é analisada à luz da teoria de Anwar Shaikh, por meio de cálculos financeiros. Os autores concluem, também, que o sistema português é auto-suficiente e que os contribuintes pagam mais do que recebem. Em 1978 foi criado o Sistema Nacional de Saúde, cujos utentes são grandes vítimas desta crise, poucos anos antes das políticas neoliberais começarem no nosso país, em 1985. O governo de José Sócrates lançou três Programas de Estabilidade de Crescimento (PEC), que os autores consideram planos de austeridade, que originaram a sua demissão, quando o quarto plano náo foi aprovado. $\mathrm{O}$ governo de Pedro Passos Coelho exacerbou esta austeridade e a Troika, FMI, CE e BCE, agudizaram ainda mais a situação. Desde o início da crise, em 2008, que falta neutralidade ao Estado português. O Estado-providência é sustentável, ao contrário do que afirmam! Os aposentados, os desempregados, os doentes e os funcionários públicos têm sido as suas maiores vítimas.

Raquel Varela escreveu «Ruptura e Pacto Social em Portugal» voltando à época da I República e do Estado Novo, onde nos diz que as políticas sociais tiveram origem no 25 de Abril, quando se começou a estabelecer um sindicalismo de classe organizado. E elabora uma breve história das lutas políticas e das conquistas sociais em Portugal, nas últimas quatro décadas. Coloca-se a hipótese de os direitos sociais em Portugal terem sido conquistados nos 19 meses de período revolucionário e de que os factores políticos foram cruciais (juntamente com factores económicos) para a instalação do neoliberalismo, nas últimas três décadas. No $1^{\circ}$ de Maio de 1974 , houve gigantescas manifestaçóes por todo o país. A 28 de Março de 1988 é convocada a primeira greve geral contra as políticas neoliberais. Desde então, a situação social portuguesa vem-se degradando muito, estando a crise a destruir o pacto social.

Em «As Contas Reais do Serviço Nacional de Saúde e os Efeitos do Programa da UE», Eugénio Rosa, economista e sindicalista, diz-nos também que o funcionamento do SNS está em perigo, com o aumento brutal das taxas moderadoras, tendo ainda ocorrido muitas privatizaçóes abusivas. Em 2012, aprovou-se uma lei que reduziu ainda mais os fundos para a saúde. $\mathrm{O}$ autor sugere um debate público sobre questóes de saúde e um combate ao desperdício, má utilização e subutilização dos meios.

Maria Augusta Tavares, no seu artigo «Imigraçáo e Imigrantes em Portugal. O Estado de Todos Existe para Cada Um?» informa-nos que a decisão de migrar é, geralmente, dura, motivada pelo desemprego. A migração internacional não é uma decisão individual, como advoga a teoria neoclássica. A imigração reduz os custos de produçáo e os imigrantes, em Portugal, estão expostos a inúmeras contradições sociais, e a sua integração não é fácil. Recorrendo a dados de diversas pesquisas, a autora procura desfazer mitos e estereótipos, servindo-se da sua "perspectiva crítico-dialéctica», combatendo a vigente "guerra ao marxismo cultural», uma vez que o «Estado de todos inexiste para cada um».

Em «O Estado Social Europeu tem Futuro?» Elaine Rossetti Behring, partindo da "perspectiva crítico-dialéctica», questiona o futuro do espaço geopolítico do continente onde mais se desenvolveu a política social: a Europa. Desde as operaçóes de salvamento das instituiçốes financeiras, em 2009, verifica-se o crescimento exponencial do desemprego endémico e da precarização do trabalho. Traçando uma breve história da política social no capitalismo contemporâneo, 
a autora considera que a Teoria Geral de Keynes, publicada em 1936, agregada ao Pacto Fordista possibilitaram o Welfare State. Porém, o Maio de 1969 e a alta dos preços do petróleo em 1973-1974, vieram abalar a protecção social. Há, hoje, uma incompatibilidade entre acumulação e equidade a ser resolvida, tornando-se urgente ampliar o conceito de Segurança Social.

Quem Paga o Estado Social em Portugal é uma obra de economia política e uma crítica ao neoliberalismo pioneira no nosso país, que reúne contributos interdisciplinares muito completos, nos seus temas e alcance internacionais. A ordem dos artigos poderia ser alterada, ainda que isso não retire a responsabilidade a algumas empresas do nosso país pela crise actual, que não é da exclusiva responsabilidade dos EUA nem da Europa. De resto, trata-se de uma excelente história dos silenciados desta crise do capitalismo mundial e da Europa, tantas vezes torturados pela economia. Neles reside a esperança de um futuro melhor.

Como afirma Raquel Varela «Não é possível separar a economia da política. Por isso, quem mais pensou e mais longe foi no estudo do capitalismo, dos seus limites, da sua transformação, Karl Marx, fê-lo sobre o signo da economia política.» (p. 18)

Ana Rita Veleda Oliveira Doutoranda CES/FLUC

MÜHLEN, Patrik von zur - Caminhos de Fuga Espanha-Portugal. A emigração alemã e o êxodo para fora da Europa de 1933 a 1945. Coimbra: Imprensa da Universidade de Coimbra, 2012.

Rezensear o livro "Caminhos de Fuga Espanha-Portugal. A emigração alemã e o êxodo para fora da Europa de 1933 a 1945" da autoria de Patrick von zur Mühlen não é fácil, uma vez que nos coloca perante a tarefa de avaliar a pertinência da publicação não só em termos da qualidade da obra como também da sua actualidade. Trata-se, na verdade, da edição em língua portuguesa, de um estudo publicado pela primeira vez, em versão alemã, há mais de vinte anos. Nessa altura, eu próprio tinha começado a trabalhar sobre a temática dos refugiados alemães em Portugal, inspirado pela enorme quantidade de estudos publicados ao longo dos anos de oitenta do século XX sobre o êxodo dos intelectuais, cientistas e artistas alemães na sequência da tomada de poder de Adolf Hitler. Quando, na altura, soube da publicação do livro de Patrick von zur Mühlen sofri de uma espécie de choque julgando que a minha própria investigação se teria tornado obsoleta. No entanto, a leitura do livro mostrava-me que os resultados deste investigador náo eclipsariam nem a minha investigação nem a de nenhum dos autores que trabalhou até agora sobre a temática dos refugiados em Portugal, como por exemplo Irene Pimentel, Avraham Milgram, etc. Igualmente, a publicação destas obras, apesar de ocorrida quase duas décadas mais tarde, náo desactualiza ou refuta a investigação de von zur Mühlen. Pois, a temática deste autor não são «os refugiados em Portugal», mas, como indica o título da obra "os caminhos de fuga". Em outras palavras, o objectivo desta obra é o retrato das dificuldades dos refugiados que fugiram pela «rota ibérica», o principal caminho de saída da Europa após o deflagrar da 2a Guerra. Este é o motivo que leva o autor a organizar o seu livro em torno de três blocos: "A França, País de Saída", "Espanha, país de trânsito" e finalmente "Portugal, final de uma etapa".

Desde o início do terror nazi, a França foi, por razóes históricas e geográficas, 